\title{
Implementasi Framework Twitter Bootstrap Dalam Perancangan Aplikasi Penerimaan Mahasiswa Baru Berbasis Web
}

\author{
Mochamad Alfan Rosid ${ }^{*}$, Ribangun Bamban Jakaria ${ }^{2}$ \\ 1,2Universitas Muhammadiyah Sidoarjo \\ alfanrosid@umsida.ac.id ${ }^{* 1}$, ribangunbz@umsida.ac.id ${ }^{2}$
}

\begin{abstract}
Abstrak
Dalam mendesain template aplikasi berbasis web, programmer web menggunakan sintak-sintak CSS untuk membuat tampilan menjadi lebih menarik. Dalam perkembangannya banyak tools atau framework CSS yang dapat dimanfaatkan untuk mempercepat pengerjaan desain template web, diantaranya Gumby, Foundation, Less Framework, Blueprint CSS dan Twitter Bootstrap. Dari beberapa framework CSS tersebut, Twitter Bootstrap hadir dengan tutorial dan dokumentasi yang berlimpah serta memiliki fitur responsive. Pada penelitian ini penulis mengimplementasikan framework Twitter Bootstrap pada perancangan aplikasi penerimaan mahasiswa baru berbasis web. Tahapan yang diambil dalam perancangan Aplikasi Penerimaan Mahasiswa Baru ini diawali dengan download Twitter Bootstrap dari website resminya dan melakukan ekstraksi ke folder project setelah itu baru class-class yang disediakan oleh twitter Bootstrap dapat dipanggil dalam pengerjaan desain aplikasi. Dengan penerapan framework twitter bootstrap ini pengerjaan desain aplikasi lebih cepat karena tidak perlu lagi memikirkan sintak-sintak css dan menghasilkan template yang responsive, ringan, dan simple.
\end{abstract}

Kata Kunci: Web, CSS, Twitter Bootstrap

\begin{abstract}
In designing web-based application template, a web programmers is using CSS syntax to make the attractive display. Less Framework, Blueprint CSS dan Twitter Bootstrap. There are many CSS tools and framework that could be utilized to help making web template design such as Gumby, Foundation, Less framework, Blueprint CSS and Twitter Bootstrap. From those CSS framework, Twitter Bootstrap has many tutorials and the most responsive features. In this research, a web-based application for new students registration is implemented by using Twitter Bootstrap framework. The steps begin by downloading Twitter Bootstrap from the official website and extracting it to the project folder; after that the classes provided by Twitter Bootstrap could be used in application design. By implementing this Twitter Bootstrap framework, the application design would be significantly faster because we do not need to think about the CSS syntax to create the light, simple, and responsive template.
\end{abstract}

Keywords: Web, CSS, Twitter Bootstrap

\section{Pendahuluan}

Pembuatan aplikasi berbasis web pastinya tidak akan lepas dari mendesain template, yang mengharuskan programmer meluangkan banyak waktu untuk menuliskan sintak-sintak CSS. CSS ini digunakan agar tampilan web menjadi lebih menarik. Saat ini banyak sekali tools atau Framework CSS yang dapat dimanfaatkan untuk mempercepat pengerjaan desain template web, diantaranya Gumby, Foundation, Less Framework, Blueprint, CSS, dan Twitter Bootstrap. Dari beberapa Framework CSS tersebut, Twitter Bootstrap hadir dengan tutorial dan dokumentasi yang berlimpah serta memiliki fitur responsive.

Dari penelitian ini penulis menerapkan Framework Twitter Bootstrap untuk mendesain Aplikasi Penerimaan Mahasiswa Baru Berbasis Web, sehingga proses pengerjaan jauh lebih cepat, dan programmer tidak perlu lagi memikirkan sintak-sintak CSS yang mengatur style aplikasi berbasis web. Selain itu, tampilan web yang dihasilkan menjadi simple, responsive, stylish, dan ringan. 
Rahman A, dkk [1] menggunakan AngularJS dan Joomla untuk membuat aplikasi web responsive, dapat beradaptasi atau menyesuaikan dengan device yang digunakan AngularJS merupakan Single Page Aplication Framework sederhana dengan kode Javascript. Merancang website dengan AngularJS dapat meningkatkan user experience, usability, visual design, dan penataan konten.

Peng, dkk [2] mengajukan konsep desain web responsive untuk mobile learning, sebelum adanya teknologi web responsive yang ada saat ini, terdapat dua masalah inti, yakni kontradiksi terlalu banyaknya resource yang dibutuhkan dan terbatas pada smartphone, kemudian yang kedua adalah perbedaan antara desain responsive dan user experience. Web responsive mungkin tidak cocok untuk semua jenis web. Dengan demikian, berbagai jenis teknologi baru diperlukan untuk meningkatkan secara terus menerus, sehingga semakin banyak resource dapat diadopsi untuk desain web responsive.

Balasubramanee, dkk [3] menjelaskan penelitian menggunakan Twitter Bootstrap dan Framework AngularJS untuk mengatasi keseimbangan antara desain dan implementasi, memberdayakan developer untuk membuat website lebih stylish dan mudah dalam maintenance. Twitter Bootstrap menyediakan pengguna dengan tampilan yang sama pada semua perangkat tanpa kehilangan fungsionalitas pengguna, sedangkan AngularJS menyediakan fitur filter tanggal dan elegan.

\section{Metode Penelitian}

\subsection{Twitter Bootstrap}

Twitter Bootstrap adalah Framework yang kuat menyediakan set kelas CSS dan fungsi JavaScript untuk memudahkan proses pembangunan antarmuka halaman web. Mengaktifkan fitur desain responsif dukungan untuk menampilkan desktop maupun mobile. Situs dikembangkan dapat bekerja dengan baik pada desktop maupun mobile. Developer tidak harus bekerja dengan CSS untuk membuat website terlihat menarik atau mendukung prinsip desain responsive, kecuali diperlukan [3].

Twitter Bootstrap dapat diunduh secara gratis di website resminya, setelah itu tinggal memanggil file CSS Twitter Bootstrap pada file project website yang akan menggunakan Twitter Bootstrap. Begitu selesai memanggil Bootstrap, maka secara otomatis akan mengubah tampilan website tanpa harus melakukan pengetikan sintak-sintak CSS seperti biasa dilakukan.

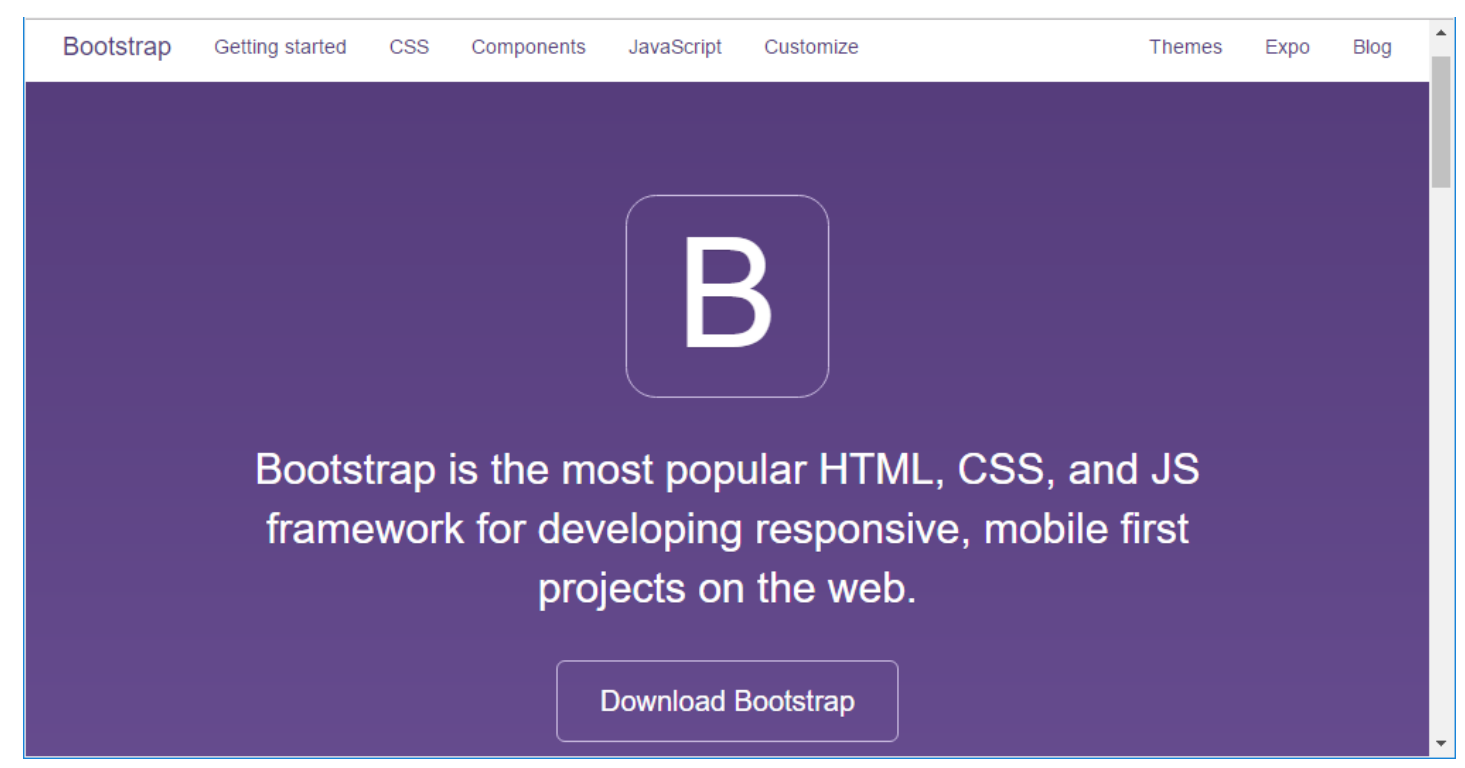

Gambar 1. Halaman Utama Website Resmi Twitter Bootstrap

Gambar 1 adalah halaman utama dari Twitter Bootstrap. Website Twitter Bootstrap telah disediakan dokumentasi lengkap cara penggunaan dan contoh template serta file Twitter Bootstrap. Hasil dari ekstraksi file Twitter Bootstrap memiliki struktur seperti Gambar 2. 


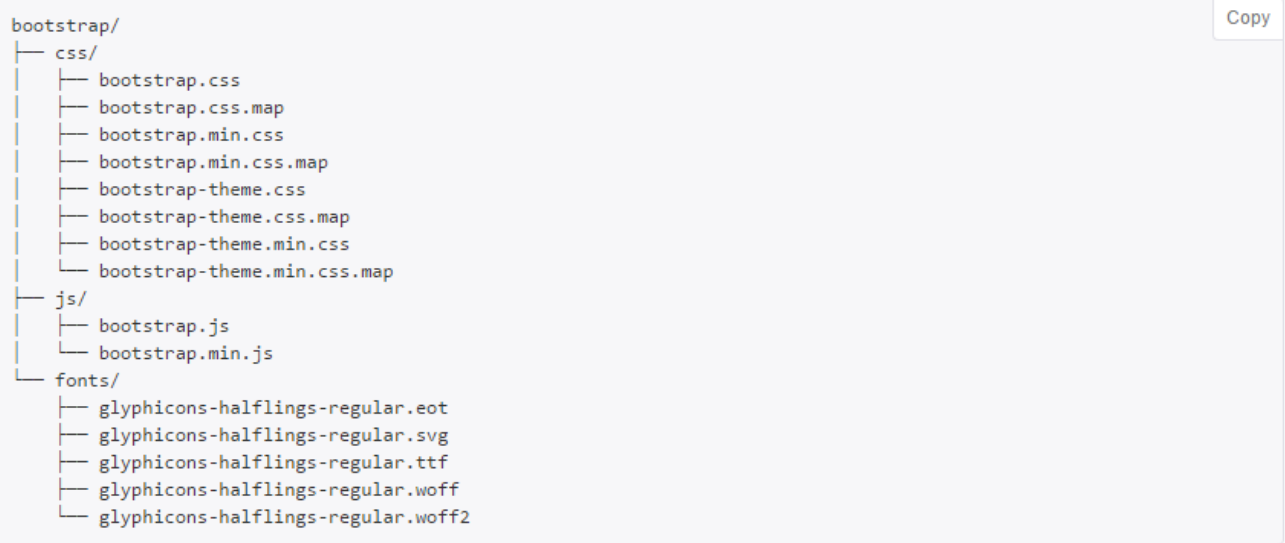

Gambar 2. Struktur File Twitter Bootstrap

\subsection{Template Dasar Twitter Bootstrap}

Pada bagian ini akan dijelaskan mengenai template dasar Twitter Bootstrap dapat digunakan untuk dasar pembuatan template Aplikasi Penerimaan Mahasiswa Baru. Adapun source code, template dasar Twitter Bootstrap ditunjukkan Gambar 3.

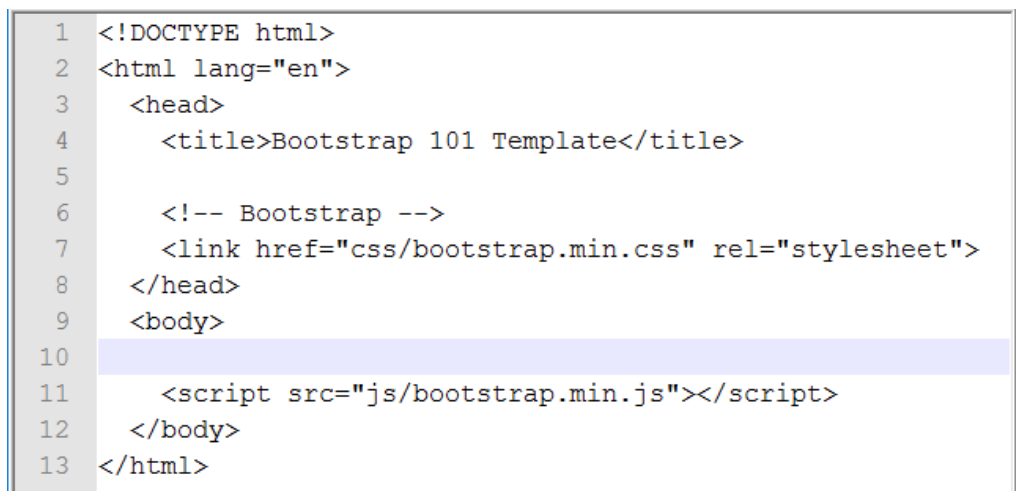

Gambar 3. Source Code Dasar menggunakan Twitter Bootstrap

Pada baris 7 Gambar 3 menunjukkan, bahwa file HTML tersebut memanggil file CSS Twitter Bootstrap, sehingga semua sintak-sintak HTML yang dituliskan di body akan mengikuti style dari Bootstrap.

Untuk membuat menu navigasi di header dapat menggunakan sintak yang di contohkan pada dokumentasi di website resmi Twitter Bootstrap. Sintak tersebut diperlihatkan Gambar 4, yang mana menunjukkan bahwa untuk mengatur style menu navigasi programmer cukup memanggil class yang sudah disediakan oleh Twitter Bootstrap, diantaranya class navigation bar, class navbar-inner, dan lain sebagainya.

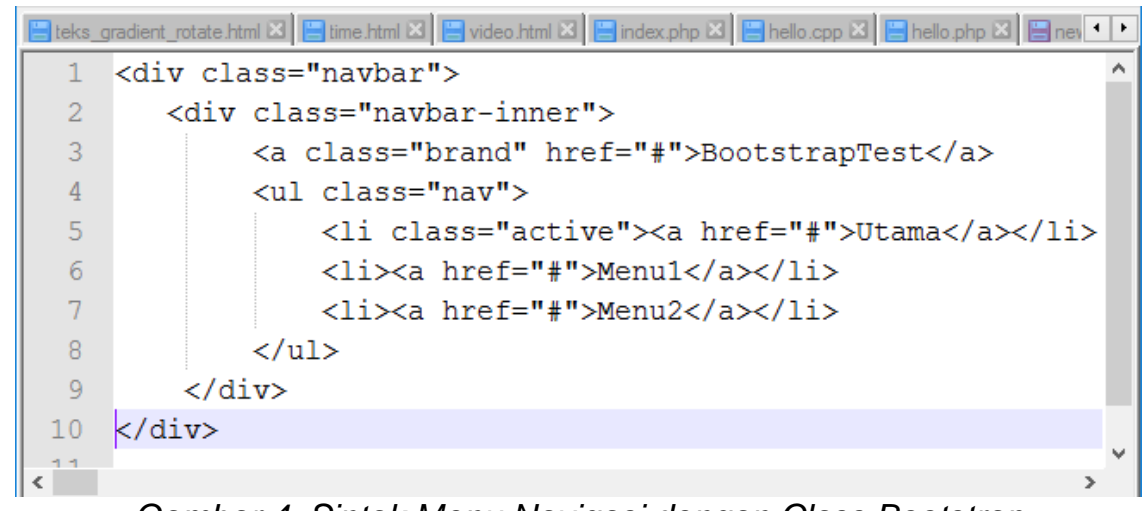

Gambar 4. Sintak Menu Navigasi dengan Class Bootstrap 
Sintak-sintak yang lain dapat dilihat pada dokumentasi di website resmi Twitter Bootstrap seperti form, tombol, Accordion, dan lain sebagainya.

\section{Hasil Penelitian dan Pembahasan}

Berdasarkan penelitian ini, Twitter Bootstrap sangat membantu pengerjaan template Aplikasi Penerimaan Mahasiswa Baru. Peneliti tidak direpotkan dengan pembuatan sintaksintak CSS yang memakan banyak waktu. Semua class dapat dimanfaatkan dalam mengatur style antarmuka, sehingga menjadi lebih menarik dan memiliki style yang seragam.

\subsection{Halaman Login}

Gambar 5 dan Gambar 6 menunjukkan hasil tampilan halaman login yang menggunakan style CSS Twitter Bootstrap, serta terlihat tampilan yang dihasilkan terlihat simpel, elegan, dan responsive.

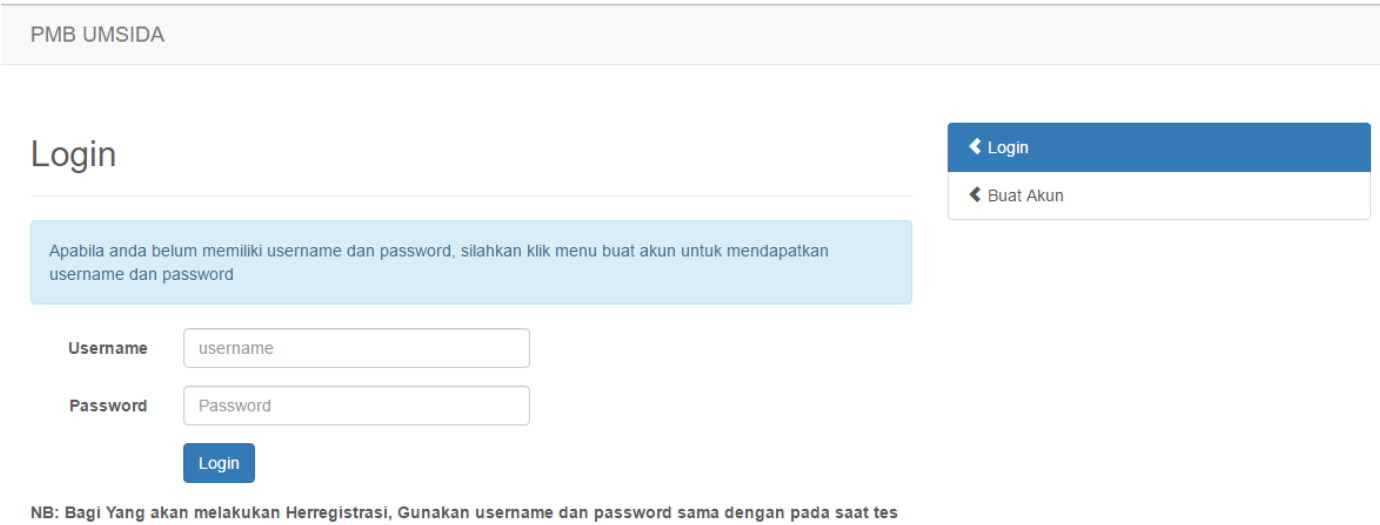

NB: Bagi Yang akan melakukan Herregistrasi, Gunakan username dan password sama dengan pada saat tes

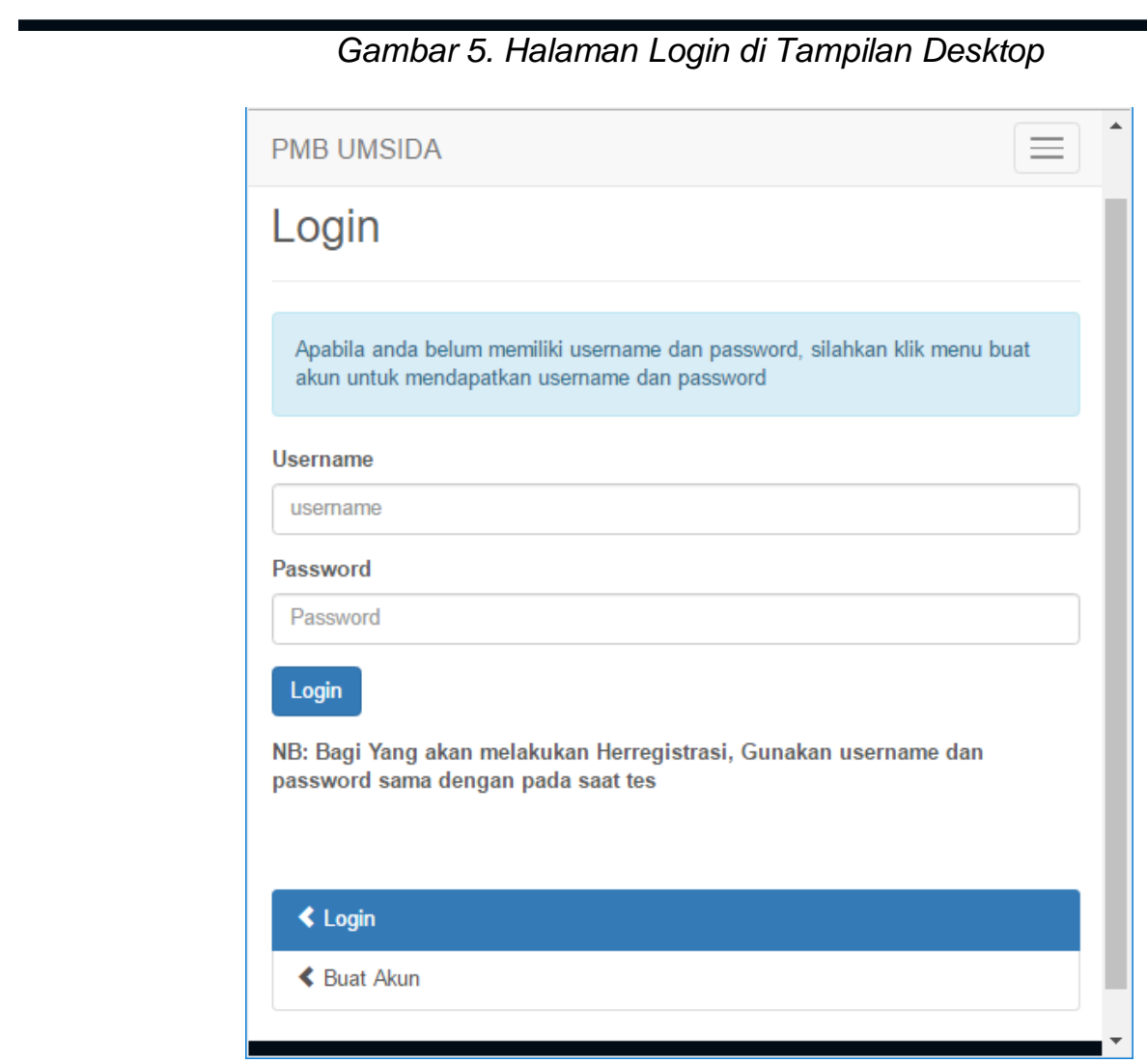

Gambar 6. Halaman Login di Tampilan Mobile

KINETIK Vol. 1, No. 3, November 2016: 129-134 


\subsection{Halaman Formulir Pendaftaran}

Pada Gambar 7 menunjukkan halaman digunakan untuk mengisi formulir pendaftaran calon mahasiswa baru.

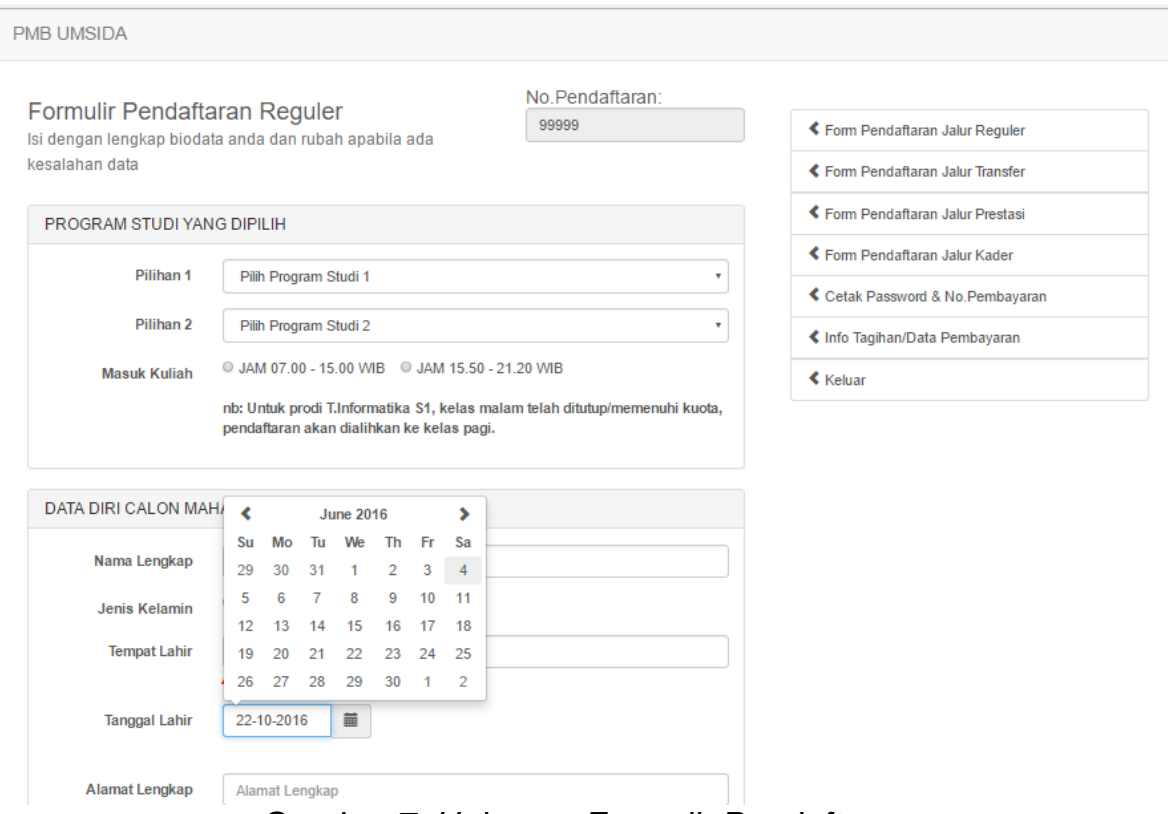

Gambar 7. Halaman Formulir Pendaftaran

\subsection{Halaman Tes Penerimaan Mahasiswa Baru}

Pada aplikasi Penerimaan Mahasiswa Baru yang dibangun juga terdapat halaman tes untuk menyaring calon mahasiswa baru dengan grade nilai yang telah ditentukan. Halaman ditunjukkan Gambar 8.

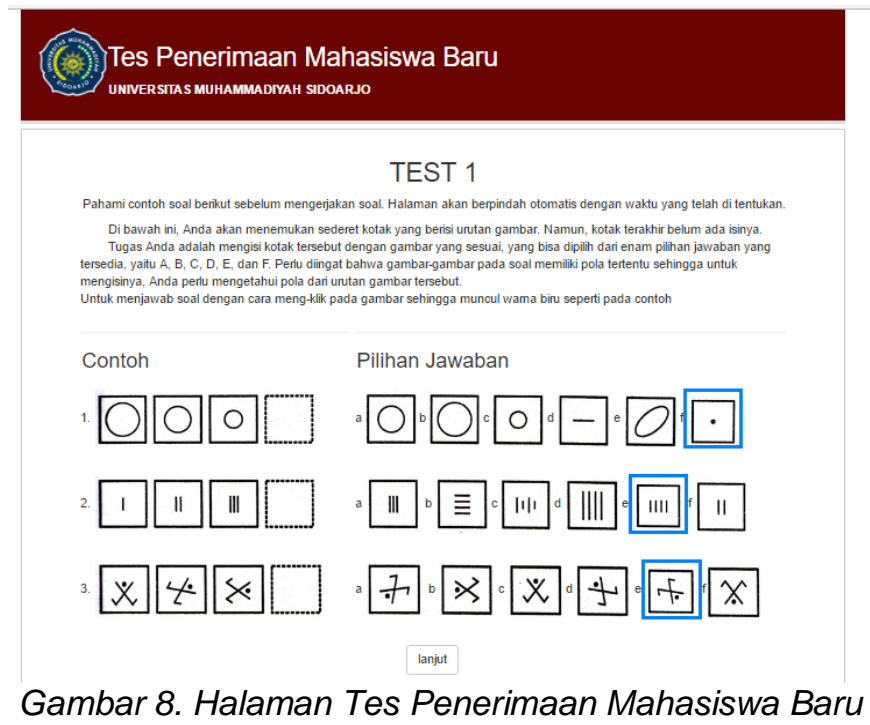

\section{Kesimpulan}

Dengan menerapkan Framework Twitter Bootstrap, proses perancangan Aplikasi Penerimaan Mahasiswa Baru menjadi lebih cepat. dikarenakan sintak-sintak CSS sudah disediakan. Tampilan tiap halaman menjadi seragam mengikuti style Bootstrap. Disamping itu, tampilan yang dihasilkan terlihat simple, ringan, dan responsif terhadap perangkat yang digunakan oleh pengguna. Aplikasi Penerimaan Mahasiswa Baru dapat menunjukkan tampilan yang sama baiknya di desktop dan mobile, hal ini dikarenakan sifat responsive yang dihasilkan oleh Framework Twitter Bootstrap. 


\section{Referensi}

[1] Rahman, A. Abdur, and S. Chitra Devi. "A framework for ultra-responsive light weight web application using Angularjs." Green Engineering and Technologies (IC-GET), 2015 Online International Conference on. IEEE, 2015.

[2] Peng, Wenhui, and Yaling Zhou. "The Design and Research of Responsive Web Supporting Mobile Learning Devices". Educational Technology (ISET), 2015 International Symposium on. IEEE, 2015.

[3] Balasubramanee, Viknes, et al. "Twitter bootstrap and AngularJS: Frontend frameworks to expedite science gateway development". Cluster Computing (CLUSTER), 2013 IEEE International Conference on. IEEE, 2013. 